DOI 10.37882/2223-2982.2021.05.03

\title{
В0ЗМОЖНОСТИ ИСПОЛЬЗОВАНИЯ МЕТОДОВ АРТ-ТЕРАПИИ В РАЗВИТИИ ЭМОЦИОНАЛЬНО-ЛИЧНОСТНОЙ СФЕРЫ У ДЕТЕЙ ДОШКОЛЬНОГО ВОЗРАСТА
}

\section{POSSIBILITIES OF USING ART THERAPY METHODS IN DEVELOPMENT OF EMOTIONAL-PERSONAL SPHERE IN PRESCHOOL CHILDREN}

\section{A. Barykinskaya}

Summary: The article is devoted to the study of the possibilities of using various art-therapeutic practices in the development of the emotional and personal sphere of preschool children. The author gives a brief description of art therapy, postulates on a significant variety of its forms and methods. Emphasis is placed on such variations in art therapy as music therapy, vocal therapy, dance therapy. Also, such a format of arttherapeutic practice as game therapy is considered. It is concluded that art therapy, including, together with psycho-gymnastics, work not only to develop the emotional and personal sphere of preschool children, but also to preserve their physical and mental health, as well as prevent emotional disorders.

Keywords: art therapy, music therapy, vocal therapy, dance therapy, game therapy, psycho-gymnastics, emotional and personal sphere, preschool age.

\author{
Барыкинская Александра Михайловна \\ аспирант, ОЧУВО «Международный инновационный \\ университет», г. Сочи \\ KhokhlovaEA@noumei.ru
}

Аннотация: Статья посвящена изучению возможностей использования различных арт-терапевтических практик в развитии эмоционально-личностной сферы детей дошкольного возраста. Автором дается краткая характеристика арт-терапии, постулируется о значительном разнообразии ее форм и методов. Делается акцент на таких вариациях арт-терапии, как музыкотерапия, вокалотерапия, танцетерапия. Также, рассматривается такой формат арттерапевтической практики, как игротерапия. Делается вывод о том, что арттерапия, в том числе, совместно с психогимнастикой работают не просто над развитием эмоционально-личностной сферы детей дошкольного возраста, но и на сохранение их физического и психического здоровья, а также предупреждение эмоциональных расстройств.

Ключевые слова: арт-терапия, вокалотерапия, танцетерапия, игротерапия, психогимнастика, эмоционально-личностная сфера, дошкольный возраст.

его познавательной и эмоциональной сфер и видят в ней богатый потенциал для гармонизации его психики [6, с. 54]. Э. Крамер, опираясь на психоаналитическое понимание процесса психического развития и творческой активности, в значительной мере связывает ее терапевтические возможности с тем, что в процессе занятий ребенка рисованием происходит организация психических процессов и постепенный переход от относительно примитивных форм психической деятельности к более сложным и эффективным [9, с. 15].

Арт-терапия включает в себя широкий спектр направлений работы, среди которых музыкотерапия, вокалотерапия, танцетерапия. Рассмотрим их более подробно.

\section{Музыкотерапия}

В наше время дети слушают музыку разных жанров. И беспокоит то, что дети мало знают классическую музыку, а подчас совсем её не воспринимают. А ведь классическая музыка - это лучшее, отобранное временем наследие человечества. Осмысленное прослушивание 
музыки, изучение значимых музыкальных произведений активизируют мышление, память, внимание; развивают чувственное познание - ощущение и восприятие; укрепляют психическое здоровье детей. Это давно доказано музыкальной психологией, которая как наука зародилась в недрах философии. Ещё античные мыслители, размышляя о законах устройства миропорядка и общественной жизни, сделали ряд важных наблюдений и выводов, касающихся роли и значения музыки в общественной жизни [7, с. 41].

Музыкальное искусство в обществе содействует его гуманизации и участвует в эстетическом наполнении общественной жизни. «Музыка - одно из самых сильнейших орудий воспитания каждого человека», - писал Д.Д. Шостакович [2, с. 86].

За последние годы в нашей стране и за рубежом вышли книги, посвящённые методике слушания музыки $[1,5,8]$ : эти вопросы, а также пропаганда музыки среди школьников и молодёжи всё больше привлекают к себе внимания учителей музыки, психолого-педагогической общественности.

Любить музыку - значит испытывать потребность в общении с ней, переживать радость, волнение, печаль, слушая её. Понимая музыку - значит воспринимать её сознательно, отдавая себе отчёт в её содержании.

Исследователи подтверждают благотворное влияние слушания классической музыки не только на умственные способности человека, но и на развития его мозга в целом. Музыкальная психология предлагает использовать музыку в целях сохранения и укрепления психосоциального здоровья, предлагая её как для слушания, так и для исполнения и творчества [13, с. 77].

Музыка - это живое знание и представление человека о самом себе, средство самопознания и самовыражения. Музыка ощущается связками, мышцами, движением, дыханием. Основной акцент ставится на приобщение детей к произведениям «золотого фонда» музыкальной культуры. Музыкальные произведения подбираются с учетом настроения детей, их эмоционального состояния. Для того чтобы музыка подействовала на ребенка, его необходимо настроить, подготовить: попросить сесть в удобной позе, расслабиться и сосредоточиться на звуках. Музыку нельзя слушать без должного внимания, отвлекаясь на какие-то посторонние дела.

Музыка как, пожалуй, никакое другое искусство, может влиять на настроение и создавать его. Все музыкальные произведения можно условно разделить на активизирующие, тонизирующие и расслабляющие, успокаивающие.
Для детей, которым свойственная пассивность (заторможенность) необходимо использовать активизирующую музыку, которая повышает генерацию возбуждения в коре головного мозга ребенка и стимулирует, таким образом, его общий жизненный тонус [5, с. 21]. Возбужденные или гиперактивные дети, наоборот нуждаются в прослушивании музыкальных произведений с умеренным, медленным темпом, снижающим общие гипер-возбудимое состояние коры головного мозга [5, с.22]. Безусловно, разнообразие типов поведения детей невозможно заранее предусмотреть. Очень многое зависит от состояния ребенка в конкретный момент и умелых методических действий творчески работающего педагога.

Для регуляции, повышения эмоционального тонуса, снятия психоэмоционального возбуждения, детям сначала дается прослушивание мелодии созвучное настроению детей, затем постепенно меняем характер музыки в соответствии с желаемой переменой. Можно использовать музыкальные произведения, составленные из фрагментов разных по характеру и звучанию. При этом в первую очередь выбираются музыкальные композиции, в которых преобладает мелодия с отчетливым ритмом [1, c. 154].

\section{Вокалотерапия}

Вокалотерапия - это терапевтическая методика, основанная на пении и определенной системе упражнений, которая позволяет стимулировать внутренние органы человека, а также нормализовать функциональность нервной системы, и повысить сопротивляемость организма к неблагоприятным внешним факторам.

Вокалотерапия - не только инструмент развития эмоционально-личностной сферы, но и активный метод коррекции природных данных: голоса, слуха, чувства музыкальной формы рассматривается, прежде всего, с позиции овладения техникой звукоизвлечения. Звук имеет над нами удивительную власть: он может и растрогать, и ранить, и избавить от боли. В звуке голоса, его интонациях проявляется отношение человека к миру, к людям, к самому себе. Поэтому голос - это, прежде всего, тест для определения качественного состояния личности - её цельности, внутренней сбалансированности. В свою очередь, работа над техникой грамотного звукоизвлечения является эффективным методом коррекции как психического, так и физического состояния человека.

Какие только оттенки чувств и настроений способен выразить и передать наш голос. И все эти разнообразные по высоте, силе и окраске звуки рождаются в гортани. Оказалось также, что и говорящий и поющий человек 
пользуются, в сущности, одними и теми же средствами выражения эмоций. Когда мы говорим или поем, то при этом включаем в работу довольно большой комплекс мышц. Так, если мышцы работают неправильно, как при спазме, это сразу приводит к нарушению лимфо- и кровотока. Хуже начинают снабжаться кровью и другие органы. Детский голосовой аппарат по размеру меньше, чем у взрослых, и менее совершенен. Во время роста ребенка голосовой аппарат также непрерывно растет и развивается, постепенно превращаясь в голосовой аппарат взрослого [2, с.4].

В силу возрастных особенностей объем, тембр и сила голоса у детей и у взрослых различны. Малый размер голосовых связок и недостаточная эластичность мышц гортани обуславливает малую звучность голоса и небольшой объем, затрудняет процесс правильного звукообразования. Малоподвижность мышц полости рта и языка затрудняет процесс выработки правильной артикуляции при пении. Короткое дыхание затрудняет выработку протяжного, напевного звука.

Так как голосовые возможности детей дошкольного возраста невелики, то и певческие навыки их элементарны, несложны. Однако в пределах любого возраста существуют индивидуальные особенности голоса. У детей старшего дошкольного возраста часто наблюдаются резкие индивидуальные различия в диапазоне и характере звучания голоса. Различия наблюдаются и в степени протяжности звука, напевности. Есть дети, поющие протяжным, напевным голосом, но в основном большинство почти «говорят» в ритме песни. Эти различия в основном вызываются тем, что как голос, так и музыкальный слух детей изменяются, развиваются, и их развитие может быть различным. Если же голос и музыкальный слух развиваются равномерно, ребенок поет верно, протяжно, естественным звуком [9, с.51].

В устранении индивидуальных недостатков в пении детей основное значение имеет установление причин, мешающих ребенку петь верно. В некоторых случаях соответствующая методика может быстро исправить недостатки, а иногда на это нужно предоставить время.

Пение развивает голосовой аппарат, укрепляет голосовые связки, улучшает речь (врачи-логопеды используют пение при лечении заикания), способствует выработки вокально-слуховой координации. Правильная поза регулирует и укрепляет дыхание [12, с. 44].

Занятия по вокалотерапии направлены на формирование оптимистического настроения. С этой целью используются песни-формулы, которые способствуют гармонизации внутреннего мира ребенка, отдельные песенки, основанные на самовнушении положительных установок.

Помимо жизнеутверждающих песен-формул в занятии с дошкольниками включаются знакомые, оптимистические по содержанию песни, которые исполняются под фонограмму группой детей. Такое исполнение является коррекционной поддержкой, дающей возможность ребенку почувствовать уверенность во время пения, наполняющей положительными эмоциями от коллективной вокальной деятельности [9, с. 52].

\section{Таншетерапия}

Танцетерапия или танцевально-двигательная терапия представляет собой направление психотерапии, в котором танец и движение используются как процесс, который способствует эмоциональной и физической интеграции человека. Следовательно, данный инструмент арт-терапии, помимо актуальной ценности в контексте развития эмоционально-личностной сферы ребенка, так же выступает средством оздоровления детского организма.

Использование различных движений для оздоровления человека, тренировка его выносливости и силы со времен Древней Эллады и Спарты до наших дней являются одними из основных методов терапии. Практически ни одно заболевание не лечится без применения различных гимнастических упражнений и лечебной физической культурой (ЛФК).

Музыкально-ритмические движения как один из терапевтических методов, в отличие от спорта, стал применяться сравнительно недавно, но уже завоевал признание, особенно за рубежом. Каждому занятию танцами предъявляются требования, как с точки зрения его художественной ценности, так и в отношении здоровья детей. Это, прежде всего, касается величины физической нагрузки, ее соразмерности возрастным показателям ребенка. Дети нуждаются в частой смене движений. Длительное сохранение статического положения для детей крайне утомительно. В то же время движения детей еще недостаточно организованы, плохо координированы, запас целенаправленных двигательных навыков у них невелик, они нуждаются в его пополнении и усовершенствовании [14, с. 42].

Относительная слабость мускулатуры и гибкость костей из-за большой прослойки хрящевых тканей могут привести к образованию плохой осанки и искривлению позвоночника. Двигательный аппарат ребенка еще недостаточно окреп, что вызывает необходимость очень внимательного отношения к дозировке упражнений.

Мышечная работа является важным биологическим 
фактором развития детей. Известный афоризм «Движение - это жизнь» точно отражает позитивное влияние движений, особенно еще на несформировавшийся организм ребенка. Дети не могут находиться без движений. Оптимальный тонус мышц брюшного пресса и диафрагмы способствует оптимизации дыхания и легочной вентиляции и тем самым обогащению крови кислородом.

Чтобы привести ослабленные мышцы в состояние достаточного напряжения, активности, их необходимо включить в постоянную работу. Танцетерапия, которая используется на музыкальных занятиях, является одним из совершенных вариантов восстановления упругости и силы мышечной ткани, так как использует в своем арсенале многообразие различных движений [1, с. 21].

Танцетерапия эффективна, экономична, а также лояльна по отношению к ребенку. Можно лечить искривление позвоночника на больничной койке, а можно в танце, когда ребенок и не догадывается, что при занятии любимым делом он проходит курс восстановительного лечения.

В спектр арт-терапевтических практик также входит игротерапия. Игровая терапия - один из главных методов психологической работы с детьми дошкольного и школьного возрастов, поскольку игра для ребенка является привычной и естественной формой деятельности. Через игру ребенок учится общественным правилам и нормам поведения, установлению отношений и связей с окружающими. Поэтому игротерапия позволяет успешно решать различные проблемы детей дошкольного возраста в удобном и знакомом для них формате.

По определению психолога Г.Л. Лэндрета: «Игровая терапия определяется как динамическая система отношений между ребенком и педагогом, обученным процедурам игровой терапии, который обеспечивает ребенка игровым материалом и облегчает построение безопасных отношений для того, чтобы ребенок мог более полно выразить и исследовать собственное Я (чувства, мысли, переживания и поступки) с помощью игры - естественного для ребенка способа коммуникации» [11, с. 57]. Игротерапия - это процесс совместного с ребенком проживания и осмысления какой-либо жизненно важной ситуации, поданной в игровой форме. Это процесс сотворчества, содействия, сопереживания, в котором ребенок и взрослый идут по дороге откровений, открытий и побед.

Игра для ребёнка - естественный способ рассказать о себе, своих чувствах, мыслях, о своём опыте. Детям бывает очень непросто поделиться со взрослыми, да и друг с другом своими переживаниями и чувствами. Но все свои чувства, весь свой полученный опыт они легко, непринуждённо и естественно могут прожить в игре, выбрав определённый игровой материал, действуя с ним определённым образом. Разыгрывая и тем самым, проживая вновь и вновь определённые ситуации. Всё это даёт возможность чуткому и мудрому взрослому постичь «ландшафт детской души». Игра предоставляет уникальную возможность ребёнку реорганизовывать, преображать свой опыт, свой личный мир [10, с. 38].

Психолог В. Экслайн рассматривала игру как процесс, в котором ребёнок проигрывает свои чувства, таким образом, выводя их на поверхность, вовне, получая возможность взглянуть на них со стороны или научиться управлять ими, либо отказаться от них. Действительно, зачастую наши беседы, увещевания «не греют детскую душу». Они, быть может, и понятны, и принимаются ребёнком, но всё это не есть их собственный опыт, не их личный выбор и не ими принятое решение. Как часто мы предлагаем детям нюхать срезанные цветы, лишая их возможности выращивать прекрасные цветы самим [11, C. 59].

Выработка механизмов торможения подкрепляется упражнениями под музыку. Если можно считать прочно установленной зависимость моторики от психического состояния, то не следует забывать об обратном влиянии моторики на психику.

Одним из методов игротерапии является психогимнастика. Психогимнастика - это специальные этюды, упражнения и игры, направленные на развитие и коррекцию различных сторон психики ребенка, как ее познавательной, так и эмоционально-личностной сферы.

При использовании этой методики педагог на музыкальном занятии строит работу с детьми по следующим фазам [4, с. 62]:

I фаза - обучение элементам техники выразительных движений.

II фаза - использование выразительных движение в воспитание эмоций и высших чувств.

III фаза - приобретение навыков в саморасслаблении.

В психогимнастике придается большое значение общению детей со сверстниками, что очень важно для нормального развития и эмоционального здоровья детей. Детям, прошедшим курс психогимнастики, становится легче общаться со сверстниками, проще проявлять свои чувства и лучше понимать чувства других [15, с. 72]. У них вырабатываются положительные черты характера: уверенность, честность, смелость, доброта; изживаются невротические проявления: страхи, различного рода опасения, неуверенность. 


\section{ЛИТЕРАТУРА}

1. Анисимова Г.И. 100 музыкальных игр для развития дошкольников. - М.: АСТ, 2011. - 365 с.

2. Белошистая А.В. Игровые технологии в образовании и воспитании ребенка дошкольного возраста // Пед. технологии. - 2010. - № 2. - С. 3-8.

3. Дуганов Р.В. Природа творчества. - М.: Сов.писатель, 2011. - 352 с.

4. Ефремов В.И. Творческое воспитание и образование детей на базе ТРИЗ. - Пенза: Уникон-ТРИЗ, 2011. - 132 с.

5. Киселева М.В. Арт-терапия в работе с детьми: пособие. - СПб.: Речь, 2012. - 160 с.

6. Клеек Б. Интенсивный курс по развитию творческого мышления. - М.: Издательство АСТ, 2011. - 392 с.

7. Клезович 0.В. Музыкальные игры и упражнения для развития и коррекции речи детей: пособие. - М., 2010. - 198 с.

8. Козырева А.Ю. Лекции по педагогике и психологии творчества. - 2012. - 586 с.

9. крамер Э. Арт-терапия с детьми / Э. Крамер. Пер. Г.Н. Ниловой, Е.Д. Пройдаковой. Ред. Е. Макарова, С. Макарова. - М: Генезис, 2013. - 231 с.

10. Ломакина Г.Р. Сказкотерапия. Воспитываем, развиваем, освобождаем ребенка от психологических проблем. - М., 2009. - 315 с.

11. Лубовский В.И. Специальная психология: Учебник для студентов высших учебных заведений, обучающихся по дефектологическим специальностям / В.И. Лубовский, Т.В. Розанова, Л.И. Солнцева и др. // Под ред. В.И. Лубовского. - 2-е издание, исправленное. - М.: Академия, 2009. - 556 с.

12. Очаповская М.А. Особенности развития мышления детей дошкольного возраста // Дошкольное воспитание. - 2013. - №6. - С. 44-55.

13. Пономарев Я.А. Психология творчества. - М.: Издательство "Наука", 2011. - 302 с.

14. Примерная основная общеобразовательная программа дошкольного образования / Березина Н.О., Бурлакова И.А., Герасимова Е.Н. и др. / Под научным руководством А.Г. Асмолова. - М.: Просвещение, 2010. -154 с.

15. Техники и технологии коррекционно-развивающей работы с детьми и подростками / авт.-сост. Н.А. Сакович. - Минск: Красико-Принт, 2012. - 92 с.

\footnotetext{
( ) Барыкинская Александра Михайловна (KhokhlovaEA@noumei.ru).
}

Журнал «Современная наука: актуальные проблемы теории и практики»

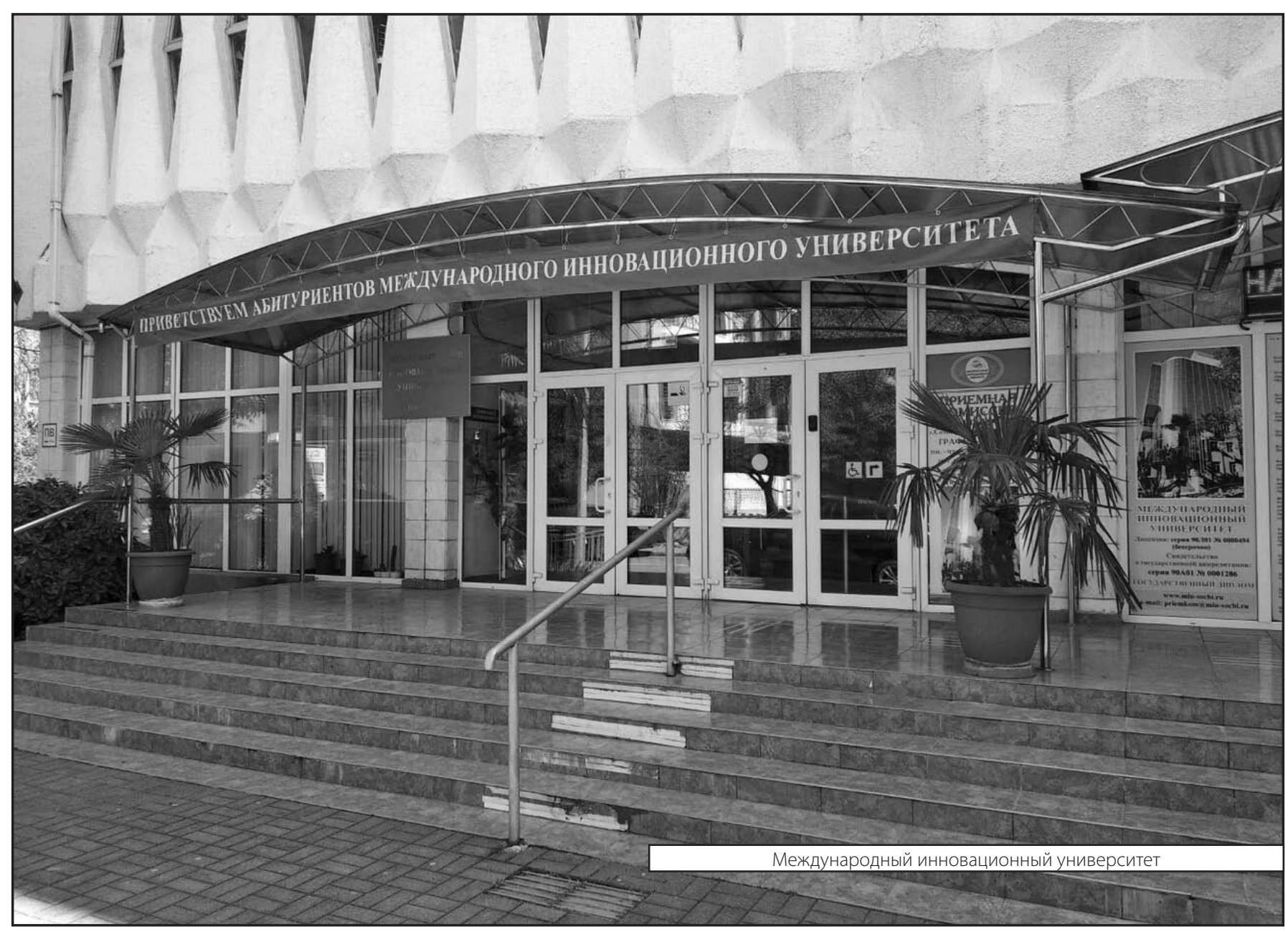

